\title{
INDICADORES PARA AVALIAÇÃO SISTÊMICA DE PROGRAMAS SOCIAIS: O CASO PRONATEC
}

PAULO DE MARTINO JANNUZZI

\section{RESUMO}

O artigo apresenta a abordagem sistêmica de avaliação de políticas e programas sociais e a natureza diversa de indicadores necessários para responder às diferentes demandas de informação para aperfeiçoamento e julgamento de mérito da ação pública. Introduzem-se três perspectivas epistêmicas de avaliação - o normativismo-burocrático da auditoria operacional, o positivismo-tecnocrático da avaliação econômica de projetos sociais e o pluralismo-metodológico da avaliação sistêmica de programas -, associando-as a diferentes concepções acerca da natureza, complexidade e valores da política social. Em seguida, discute-se a necessidade de produção de indicadores específicos para as diversas etapas de implementação de programas e para avaliação de seus componentes sistêmicos - recursos orçamentários, recursos institucionais, recursos humanos, portfólio de serviços, equipamentos e participação social. Ilustra-se como caso de avaliação sistêmica o conjunto de pesquisas e indicadores do Pronatec Brasil Sem Miséria, produzidos entre 2011 e 2016.

PALAVRAS-CHAVE INDICADORES EDUCACIONAIS • AVALIAÇÃO DO PROGRAMA • AVALIAÇÃO SISTÊMICA • POLÍTICAS SOCIAIS. 


\section{INDICADORES PARA LA EVALUACIÓN SISTÉMICA DE PROGRAMAS SOCIALES: EL CASO PRONATEC}

RESUMEN

El artículo presenta el abordaje sistémico de evaluación de políticas y programas sociales y la distinta naturaleza de indicadores necesarios para responder a las diversas demandas de información para el perfeccionamiento y juicio de mérito de la acción pública. Se introducen tres perspectivas epistémicas de evaluación - el normativismo-burocrático de la auditoría operativa, el positivismo-tecnocrático de la evaluación económica de proyectos sociales y el pluralismo-metodológico de la evaluación sistémica de programas -, asociándolas a diferentes concepciones acerca de la naturaleza, complejidad e valores de la política social. Luego se discute la necesidad de producir indicadores específicos para las diversas etapas de implementación de programas y para la evaluación de sus componentes sistémicos - recursos presupuestarios, recursos institucionales, recursos humanos, portafolio de servicios, equipos y participación social. Como ejemplo de evaluación sistémica, se presenta las investigaciones e indicadores de evaluación del programa Pronatec Brasil Sem Miséria, producidos entre el 2011 y el 2016.

PALABRAS CLAVE INDICADORES EDUCACIONALES • EVALUACIÓN DEL PROGRAMA • EVALUACIÓN SISTÉMICA • POLÍTICAS SOCIALES.

\section{INDICATORS FOR THE SYSTEMIC EVALUATION OF} SOCIAL PROGRAMS: THE PRONATEC CASE

ABSTRACT

The article presents a systemic approach of evaluation of social policies and programs and the diverse nature of indicators necessary to respond to different demands for information for the improvement and assessment of public action. It introduces three epistemic perspectives of evaluation; i.e. the bureaucratic-normativism of operational auditing, the technocratic-positivism of economic evaluation of social projects and methodological-pluralism of systemic evaluation of programs which are associated with different conceptions of the nature, complexity and values of social policies. Following this, the article discusses the need to develop specific indicators for the various stages of implantation of the programs and for the evaluation of their systemic components - budgetary resources, institutional resources, human resources, portfolio of services, equipment and social participation. The studies and indicators of Pronatec program, Brasil Sem Miséria [Brazil without Misery], conducted from 2011 thought 2016, are used as an example of the systemic evaluation.

KEYWORDS EDUCATIONAL INDICATORS • PROGRAM EVALUATION • SYSTEMIC EVALUATION • SOCIAL POLICIES. 


\section{INTRODUÇÃO}

Na escala e complexidade da política pública no país, o processo de formulação, monitoramento e avaliação de programas sociais é bastante intensivo no uso de informação e conhecimento. Revisões bibliográficas sobre a questão social de interesse, meta-avaliações sobre programas e ações desenhados para mitigá-los, diagnósticos de públicos-alvo, sistemas de acompanhamento das ações e pesquisas de avaliação de resultados compõem o quebra-cabeça informacional requerido aos formuladores e gestores para potencializar as chances de sucesso de uma intervenção. Parte significativa desse acervo estrutura-se na forma de indicadores, que constituem instrumentos-síntese de aspectos da realidade social, de processos executados ou de resultados alcançados pela política ou programa.

Os indicadores são, pois, insumos básicos e indispensáveis em todas as fases do processo de formulação, implementação e avaliação das políticas e programas públicos, sejam eles programas de qualificação da mão de obra, projetos de expansão da infraestrutura urbana, programas de transferência de 
renda, ou ações focalizadas de distribuição de alimentos. Cada fase do processo de implementação da política social - do diagnóstico à avaliação - requer o emprego de indicadores específicos, de diferentes tipos e com propriedades distintas, cada qual trazendo elementos e subsídios para o bom encaminhamento do processo (ATKINSON 2005). ${ }^{1}$

A construção de indicadores para formulação, monitoração e avaliação - ou simplesmente, em sentido lato, para avaliação - de políticas e programas não é uma tarefa trivial. Trata-se de um empreendimento técnico-científico que requer tempo, esforço metodológico e refinamentos sucessivos do conceito, do processo investigado ou do fenômeno social em questão. A dificuldade de construção de um indicador muitas vezes não é um problema intrinsecamente metodológico, mas sim proveniente da falta de clareza sobre o conceito em questão, sobre o aspecto central da mudança social a investigar ou sobre como opera o modelo de intervenção de um programa público. A construção de um indicador é, assim, um processo de aprimoramento contínuo, em que diferentes medidas vão sendo propostas em meio ao refinamento do conceito original, que vai deixando suas imprecisões e ambiguidades em direção a um constructo mais preciso e delimitado, favorecendo a especificação de um novo indicador. Trata-se, pois, de um processo interativo de conceito-medida-conceito: assim que se conhece melhor o fenômeno social em estudo, por meio de versões preliminares de um indicador proposto, é possível precisar melhor o aspecto de interesse desse fenômeno, o que permite nova especificação de conceito e suas possíveis "medidas aproximativas", "proxies" ou indicadores (JANNUZZI, 2004). Trata-se, de fato, de um processo um tanto circular, ou melhor, espiral-evolutivo. Como bem registra Neufville (1975), algumas décadas se passaram na consolidação mais efetiva de indicadores de desemprego, pobreza, qualidade habitacional ou de saúde. Imprecisões conceituais ou percepções diferentes do que se entendia - e se entende - por "falta de emprego", "iniquidade", “bem-estar" e "vida saudável”, ou ainda de como enfrentar essas questões por meio de políticas e programas adiaram por bom tempo - e continuam adiando, em
1 Vale observar que há um volume considerável de informação e conhecimento de natureza qualitativa, para além de indicadores quantitativos, necessário em atividades de avaliação de políticas e programas, como discutido em Jannuzzi (2014) 
certo sentido - a produção de indicadores consensualmente aceitos.

A dificuldade na construção de indicadores é maior em situações em que políticas e programas sociais se estruturam de modo sistêmico, envolvendo muitas atividades concomitantes, operados por muitos agentes, em contextos heterogêneos de gestão e oferta de serviços. Esse é o quadro de várias políticas públicas operadas no Brasil, no campo da saúde pública, assistência social, educação e qualificação profissional, em que o governo federal, estados e municípios compartilham responsabilidades no desenho, gestão e produção de serviços sociais para a população em todo o território. Nesse contexto, conceber e produzir indicadores torna-se mais complexo, pelos riscos de seleção de um número grande de medidas que ofusquem aquelas que, de fato, refiram-se a processos-chave a serem acompanhados ou a dimensões sociais impactadas pela natureza sinérgica da política ou programa.

O presente artigo contribui para orientar esse processo de construção de um sistema de indicadores para intervenções públicas mais complexas, trazendo em seções sucessivas elementos conceituais sobre avaliação sistêmica, indicadores de programas e, ao final, uma aplicação ilustrativa: o caso dos indicadores de avaliação sistêmica do Programa Nacional de Acesso ao Ensino Técnico e ao Emprego (Pronatec).

\section{ABORDAGEM SISTÊMICA NA AVALIAÇÃO DE POLÍTICAS E PROGRAMAS SOCIAIS COMPLEXOS}

Sistemas complexos de políticas sociais, que articulam programas de natureza universal com ações redistributivas em várias áreas setoriais, operados por agentes em diferentes níveis federativos de governo, em contextos desiguais em termos de capacidade de gestão e de perfil socioeconômico de públicos-alvo, requerem abordagens não triviais de avaliação. Para que esses sistemas de políticas e programas sociais consigam cumprir seus objetivos específicos e contribuir para maior efetividade social da ação pública, é necessário produzir informação e estudos de diferentes naturezas - levantamentos diagnósticos detalhados, sistemas de indicadores de monitoramento 
de ações, pesquisas de avaliação de processos e resultados de programas, investigação de potenciais impactos e externalidades negativas -, valendo-se de uma combinação plural de metodologias (quali, quanti e participativas), no sentido de abordar diferentes sujeitos envolvidos (beneficiários, usuários, técnicos na ponta e gestores). Esse universo de práticas, instrumentos e recursos é o que aqui se entende por avaliação sistêmica de políticas e programas sociais (JANNUZZI, 2016).

Nessa abordagem, avaliação é entendida como processo de produção de informações e conhecimentos para aperfeiçoamento das diferentes etapas no processo de formulação, implementação e avaliação da política ou programa social, considerando seus componentes sistêmicos estruturantes, tais como a disponibilidade de recursos financeiros, equipes técnicas e equipamentos físicos, os produtos e serviços entregues, os arranjos de governança e implementação e os mecanismos de participação social. Ou seja, na avaliação sistêmica, políticas e programas públicos não são entendidos como ações e projetos de curta ou média duração, operados em contextos limitados, com metas específicas a cumprir e com impactos avaliados a partir de critérios de eficiência econômica, como subentendido ou explicitado na maioria dos manuais de técnicas avaliativas de organismos internacionais.

Nesse sentido, é importante registrar as diferenças de concepção da avaliação sistêmica de políticas e programas sociais e de outras duas abordagens mais restritivas e ortodoxas na área: a auditoria operacional de programas públicos; e a avaliação econômica de projetos sociais. Produzir indicadores e estudos em uma ou outra abordagem implica escolhas metodológicas mais restritas ou mais abrangentes, que respondem, ao fim e ao cabo, a diferentes concepções de método científico, política social e do papel do Estado. Afinal, avaliação de programas públicos não é uma atividade tão somente técnica, como também não o é qualquer atividade de pesquisa. Embora os manuais aplicados na área dediquem-se em apresentar etapas, métodos e técnicas de monitoramento e avaliação como se fossem universais, neutros, livres de 
uma concepção ideológica e política fundante, as práticas na área estão longe de assim se revelarem. Encarada como campo de ciência aplicada ou como atividade técnica de gestão, a avaliação é sim uma atividade influenciada por valores humanos e ideológicos, com consequências sociais e políticas de menor ou maior escala (WEISS, 1972; VAITSMAN; PAES-SOUSA, 2009). Como bem pontuou Yanes (2009, p. 82):

[...] asumimos que las evaluaciones deben ser objetivas, pero no neutrales respecto al marco de valores y conceptos que guían a la política social y que, por ende, en el marco de investigaciones rigurosas, emiten juicios de valor. Asimismo sabemos que todo proceso de evaluación se desarrolla en un marco de colaboración y conflicto, en el que están en juego valores, intereses, aspiraciones, y conceptos, que no deben ser obviados, sino explicitados. La evaluación es un proceso de investigación en un contexto de poder, política y políticas.

Como todo campo de conhecimento, a avaliação de políticas e programas é uma atividade orientada por valores políticos e paradigmas diversos, regida por métodos e técnicas validadas por diferentes comunidades epistêmicas, produzindo resultados que podem ser colocados à prova por novas investigações. Não há produção tecnocientífica neutra e infalível, nem método e técnica com maior cientificidade do que outros no desenvolvimento das atividades de monitoramento e avaliação de programas. Falibilidade do conhecimento técnico é antes uma virtude do que uma fragilidade; denota a natureza científica e não dogmática do mesmo.

Assim, é preciso esclarecer que as concepções de avaliação - de suas práticas, instrumentos, do que é valorizado, do que deve ser medido, de como devem ser construídos os indicadores de programas - respondem a diferentes compreensões acerca da natureza de política social e do papel do Estado, como retratado de forma idealística no Quadro 1, a partir das sistematizações de modelos de Estados de Bem-Estar de Arretche (1995), Silva (2013) e Moreno et al. (2014). Na proposta aqui apresentada, entendimentos mais restritivos acerca do papel do Estado e do escopo da política social 
tendem a favorecer concepções mais ortodoxas e disciplinares do que é avaliação, de quais são os juízos de valor adotados, os procedimentos técnicos sugeridos e os profissionais a serem envolvidos no processo. ${ }^{2}$ Naturalmente, todo esforço de sistematização de ideias e conceitos em categorias específicas sempre está sujeito a questionamentos sobre a consistência, existência e pureza dos tipos ideais construídos. Existem sempre situações-sombra, que poderiam se encaixar em determinada categoria segundo alguns critérios, ou noutra, valorizando outros aspectos. O fato é que a validade e utilidade de tais classificações arquetípicas são comprovadas e falseadas à medida que passam a ser testadas para fins analíticos. Há, inclusive, quem considere que os eixos ou variáveis de classificação que garantem a instrumentalidade das tipologias são mais importantes do que as categorias criadas, as quais seriam uma das possibilidades de estruturar as análises, desde que as variáveis estruturantes sejam, de fato, relevantes para estudo do fenômeno em questão.

Auditoria operacional é o tipo de avaliação suficiente em situações em que a política social - e o papel do Estado - é residual. Nesses casos, a educação básica constitui o principal campo legitimado de intervenção pública, com acesso e progressão condicionados ao desempenho individual do usuário dos serviços, especialmente às séries superiores ou ao ensino técnico. Saúde pública pode também ser outra área de ação estatal, mas com cunho marcadamente higienista, com campanhas de vacinação pública e de saneamento urbano. Em um Estado Regulador, em que a principal função é zelar pelo cumprimento de contratos individuais, os indicadores de avaliação expressam a regularidade normativa na prestação dos serviços, a partir de um protocolo de auditoria padrão, já que a política é implementada mediante contratos de gestão com todas as normas operacionais definidas, em tese, anteriormente. Políticas sociais são entendidas como sistemas fechados, em que as normas são suficientes para estabelecer comportamentos dos agentes, inclusive dos beneficiários. Supõe-se uma capacidade de antecipação de problemas que, de fato, só é viável na oferta de serviços bastante simples, com pouca intermediação vertical. Na realidade, nem mes-
2 Devo à Tereza Campello, ministra de Desenvolvimento Social e Combate à Fome de 2011 a maio de 2016, a clareza em apontar a vinculação das abordagens de avaliação de programas sociais e de seus critérios de julgamento de mérito (legitimidade social versus eficiência econômica) a diferentes concepções de políticas sociais e de papel do Estado. 
mo em um Estado Mínimo é constatável a suficiência das normas preestabelecidas diante da realidade da operação de programas sociais, por agentes privados ou públicos. Nesse tipo de avaliação, não há comunidade epistêmica mais alinhada para a atividade do que a dos bacharéis de Contabilidade, Direito e Administração, com visão normativa e positiva do funcionamento do Estado e da sociedade.

Em perspectivas de política social como mecanismo de compensação ou correção das falhas de mercado, projetos sociais são desenhados para atender às necessidades da população mais pobre, sem recursos para compra de serviços educacionais, de saúde, de qualificação profissional nos agentes privados ofertantes. Trata-se do padrão de política social em concepções liberais de Estado, em que a eficiência econômica é o critério fundamental a garantir, inclusive, na avaliação de projetos sociais. Para tanto, estimula-se a oferta de diversos projetos sociais por amplo leque de ofertantes privados ou não governamentais, financiados pelo poder público ou diretamente pelas famílias mais pobres mediante vouchers ou auxílios governamentais que recebem. A implementação dos projetos sociais deve seguir um desenho operacional que facilite sua avaliação ao longo do tempo, por meio de indicadores de eficiência de processos e de impactos diferenciais entre beneficiários atendidos (clientes) e não atendidos, mas elegíveis por serem igualmente pobres, que, no entanto, não tiveram a sorte (!) de serem selecionados na oferta inicial dos serviços. Essa abordagem inspira-se em uma perspectiva um tanto ingênua de formulação de políticas públicas - "teoria da escolha racional" (HOWLETT; RAMESH; PERL, 2013) - ao supor o cidadão como indivíduo orientado por uma racionalidade econômica estrita.

Pesquisas de desenho experimental ou quasi-experimental são os delineamentos de avaliação preconizados nessa concepção de Estado, já que permitem - supostamente - medir impactos atribuíveis aos projetos sociais e, portanto, identificar não apenas os mais meritórios, mas também os que produzem maior benefício por unidade de gasto. Como o objetivo é, no médio e longo prazos, selecionar os projetos sociais - e os operadores - mais bem-sucedidos, emulando 
a lógica de mercado (só sobrevivem os mais eficientes e eficazes), os indicadores de interesse são os que fornecem parâmetros de eficiência dos gastos na produção dos serviços e os que medem a intensidade do desempenho individual do beneficiário atendido (caso) versus o não atendido (controle), preferencialmente junto ao mercado. Economistas de inspiração liberal e econometristas constituem a comunidade epistêmica com predileção por essa abordagem de avaliação, assim como outras em que a suposta estética da formulação matemática e precisão potencial das estimativas contam tanto ou mais do que a riqueza analítica e a consistência substantiva do modelo analítico adotado para responder às questões demandadas pelos gestores de políticas e programas (RAVALLION, 2009). Para essa comunidade, avaliações experimentais e quasi-experimentais devem ser aplicadas em todas as situações, na avaliação prévia de projetos sociais, como uma "prova de conceito", ou na avaliação somativa, como validação de mérito da ação social, sem consideração de outras alternativas mais apropriadas de avaliação diante das especificidades da questão social. ${ }^{3} \mathrm{O}$ desenho da avaliação orienta o desenho do projeto ou programa, não o contrário; o estudo-piloto não é estabelecido segundo critérios de complexidade operacional, capacidade de gestão dos agentes ou vulnerabilidade da problemática social, mas sim pela suposta "elegância” do modelo metodológico. Essas escolhas, no entanto, têm consequências indesejáveis, como registra Moral-Arce (2014, p. 20):

Por desgracia, muchos interesados, a distintos niveles, creen que se puede (y se debe) realizar evaluaciones de impacto de manera rutinaria a todos los programas. Paradojicamente, esa insistência en tratar de realizar evaluaciones de impacto de manera sistematica, puede conducir al resultado no deseado de desperdiciar recursos (que son limitados) por tratar de realizar uma evaluacion de este tipo. La insistencia ingenua de que solo los resultados de la evaluacion de impacto se deben utilizar para determinar que intervenciones deben realizarse, sin tener em cuenta la conveniencia, viabilidad y asequibilidad economica de dicha evaluacion de impacto puede
3 Uma análise mais extensa sobre os "mitos" da avaliação experimental pode ser consultada no "insuspeito" Ravallion (2009), Moral-Arce (2014) e Jannuzzi (2016). 
provocar graves distorsiones de los sistemas de monitoreo, seguimiento y evaluacion, ya que pueden llevar a la situacion extrema de que solo se termine haciendo aquello que se puede evaluar facilmente. Por el contrario, las decisiones estrategicas no deben basarse solo en hacer aquello que es facilmente evaluable, sino hacer aquello que tenga la mayor posibilidad de êxito y que sea lo mas eficaz posible.

Avaliações sistêmicas procuram atender, como já comentado, às necessidades de informação e conhecimento de políticas sociais mais abrangentes, orientadas segundo princípios de universalismo e equidade no acesso a direitos, valores fundantes do Estado de Bem-Estar Social (ARRETCHE, 1995). Supõe-se um Estado com políticas de proteção social a riscos individuais - na saúde, previdência e assistencial social - combinadas com políticas de promoção de capacidades - na educação, no trabalho, na inclusão produtiva - e ações afirmativas para equidade de etnia, gênero e origem social. Trata-se de um modelo de Estado inspirado na experiência história da Europa Continental, que contrasta claramente

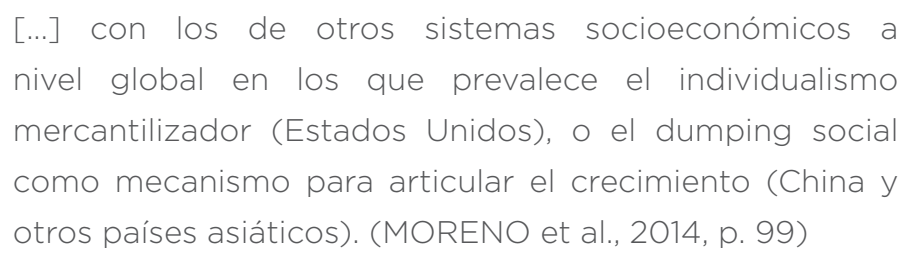

Nesse contexto, políticas e programas públicos são criados para garantir direitos sociais e melhores condições de vida ao cidadão, bem como maior justiça e coesão social para a sociedade, valendo-se, para tanto, dos desenhos operacionais e arranjos de implementação mais efetivos, considerando a complexidade da intervenção, capacidade de gestão de agentes públicos e privados e necessidades específicas de públicos-alvo segundo sua maior ou menor vulnerabilidade. Políticas e programas sociais não são bens e serviços comuns produzidos por empresas e consumidos por indivíduos como em um mercado "racional" de trocas, mas formulados e moldados segundo interação de diversas instituições, agentes e percursos históricos (HOWLETT; RAMESH; PERL, 2013). 
Indicadores de regularidade normativa, derivados de protocolos de auditoria operacional, são usados nessa abordagem como recurso de gestão. Eficiência e impacto são também dimensões a serem retratadas por indicadores em avaliações sistêmicas, valendo-se, quando adequado, de modelos econométricos usados na avaliação de projetos, com as adaptações necessárias para não transigir com questões éticas acerca da seleção de beneficiários dos programas (JANNUZZI, 2016). Mas, para além da sustentabilidade financeira e eficiência econômica da política social, a avaliação sistêmica produz evidências da contribuição de políticas e programas segundo um conjunto mais amplo de valores e princípios da atuação do Estado, como cobertura e equidade de acesso a diferentes públicos, qualidade dos serviços e contribuição para promoção de acesso a direitos sociais, redução da desigualdade e maior coesão social. Tais dimensões acabariam por fortalecer a legitimidade social das políticas, assegurada, de partida, pela legitimidade política que Estados republicanos garantem aos governos eleitos e suas escolhas de agendas prioritárias. Legitimidade social é, pois, um valor a se contrapor ao pressuposto da eficiência econômica no julgamento do mérito das políticas públicas.

Avaliação sistêmica requer, nesse sentido, o envolvimento de equipes multidisciplinares, compostas por técnicos envolvidos diretamente com as políticas e especialistas externos, com uma abordagem multimétodos de pesquisas de avaliação, crença na natureza contingencial do conhecimento técnico-científico e reconhecimento da perspectiva técnico-política da decisão em políticas públicas. Afinal, a avaliação sistêmica é um processo de aprendizado organizacional para políticas sociais, plural em perspectiva metológica, contrapondo-se às soluções um tanto ingênuas ou simplificadoras prometidas pelo "normativismo" burocrático das auditorias operacionais ou pelo "positivismo" tecnocrático dos exercícios econométricos de avaliação de projetos sociais.

A exposição de um programa social de certa complexidade, como o Programa Nacional de Acesso ao Ensino Técnico e Emprego, pode ajudar na demonstração da utilidade 
do marco analítico da avaliação sistêmica para orientar a produção de indicadores de avaliação de programas. Como discutido em Jannuzzi (2016), programas de qualificação profissional requerem abordagens sistêmicas de avaliação: precisam, de partida, de pesquisas diagnósticas sobre as características dos públicos-alvo atendidos, análise do grau de adequação da oferta de cursos em relação às demandas de qualificação profissional requeridas regionalmente, análise da capacidade técnica das instituições ofertantes, registro de situações de ensino/aprendizagem nas salas de aula, processo de disseminação de informações sobre os cursos e mobilização de públicos. Para além de avaliações continuadas de processos e atividades, tal estratégia envolve ainda a produção de indicadores para análise da cobertura territorial e dos públicos-alvo, do desempenho e satisfação dos participantes, dos impactos em termos de busca por emprego, participação econômica e empregabilidade dos egressos. Uma proposta de plano avaliativo com esse escopo foi implementada na avaliação do Pronatec Brasil Sem Miséria (Pronatec BSM), em parceria entre o Ministério do Desenvolvimento Social e Combate à Fome (MDS) e o Ministério da Educação (MEC), contemplando diferentes pesquisas e estudos. Em tópico mais à frente, pode-se verificar que o programa foi objeto de uma abordagem sistêmica de avaliação. 
QUADRO 1: Concepções de Estado, de política social e abordagem predominante de avaliação

\begin{tabular}{|c|c|c|}
\hline $\begin{array}{l}\text { CONCEPÇÃO } \\
\text { DE ESTADO }\end{array}$ & $\begin{array}{l}\text { NATUREZA DA POLÍTICA SOCIAL E DE SUA } \\
\text { COMPLEXIDADE OPERACIONAL }\end{array}$ & $\begin{array}{l}\text { CONCEPÇÃO PREDOMINANTE DA AVALIAÇÃO, } \\
\text { CRITÉRIOS DE JULGAMENTO DE MÉRITO, } \\
\text { INSTRUMENTOS, COMUNIDADES EPISTÊMICAS } \\
\text { ENVOLVIDAS E NATUREZA DOS INDICADORES }\end{array}$ \\
\hline $\begin{array}{l}\text { Estado } \\
\text { Regulador ou } \\
\text { Gendarme }\end{array}$ & $\begin{array}{l}\text { Educação básica e saúde pública higienista } \\
\text { (vacinação, sanitização urbana) são os campos } \\
\text { de política social, com a cobertura possível em } \\
\text { função dos recursos. No caso da educação, o } \\
\text { acesso e a progressão estão condicionados ao } \\
\text { mérito e desempenho individual. } \\
\text { Provimento dos serviços é predominantemente } \\
\text { privado ou filantrópico. } \\
\text { Normas operacionais bem definidas } \\
\text { ex-ante, mas pouco abrangentes em termos de } \\
\text { regulação. } \\
\text { Beneficiário da política é usuário. }\end{array}$ & $\begin{array}{l}\text { Avaliação como auditoria operacional, por meio de pro- } \\
\text { cedimentos padronizados de checklists ou protocolos de } \\
\text { verificação de atendimento de normas, realizadas predo- } \\
\text { minantemente por profissionais com formação em Conta- } \\
\text { bilidade, Direito e Administração, com visão normativa e } \\
\text { prescritiva da ação pública. } \\
\text { Eficácia no cumprimento do contrato de prestação de ser- } \\
\text { viços é o critério fundamental para julgamento do mérito } \\
\text { do programa. } \\
\text { Indicadores de programas medem a adequação/regulari- } \\
\text { dade normativa dos contratos de prestação de serviços. }\end{array}$ \\
\hline Estado Liberal & $\begin{array}{l}\text { Educação básica e saúde pública higienista } \\
\text { são entendidas como universais, mas a política } \\
\text { social é residual, criada como mecanismo de } \\
\text { correção de falhas de mercado voltado para a } \\
\text { população mais pobre, e operacionalizada por } \\
\text { inúmeros projetos sociais operados por organi- } \\
\text { zações não governamentais ou comprados por } \\
\text { vouchers distribuídos às famílias. } \\
\text { Projeto deve ser implantado de forma a maxi- } \\
\text { mizar a estratégia de avaliação, idealmente a } \\
\text { experimental (com beneficiários e não benefi- } \\
\text { ciários elegíveis). } \\
\text { Beneficiário da política é cliente ou consumidor. }\end{array}$ & $\begin{array}{l}\text { Avaliação econômica de projetos sociais, para análise de } \\
\text { eficiência e impactos de projetos, tomados isoladamente, } \\
\text { por meio de desenhos experimentais, realizada por agen- } \\
\text { tes externos, com predominância de econometristas, com } \\
\text { visão positivista da ciência e postura tecnocrática da ges- } \\
\text { tão pública. } \\
\text { Eficiência no uso dos recursos empregados para produzir } \\
\text { os resultados é o principal critério de mérito do programa. } \\
\text { Indicadores de programas concentram-se na medição da } \\
\text { eficiência de processos e do impacto diferencial no de- } \\
\text { sempenho dos beneficiários (em relação aos não atendi- } \\
\text { dos pelo projeto). }\end{array}$ \\
\hline $\begin{array}{l}\text { Estado de Bem- } \\
\text {-Estar Social }\end{array}$ & $\begin{array}{l}\text { Arquitetura de políticas sociais, de cunho uni- } \\
\text { versal, compensatório, redistributivo e afirmati- } \\
\text { vo, em três campos: proteção social, promoção } \\
\text { social e infraestrutura social, compreendo pro- } \\
\text { gramas como empreendimentos complexos. } \\
\text { Programa deve ser implementado da melhor } \\
\text { forma a garantir seu sucesso, segundo articu- } \\
\text { lação intersetorial e federativa e critérios de } \\
\text { capacidade de gestão, complexidade opera- } \\
\text { cional, vulnerabilidade social dos públicos-alvo. } \\
\text { Beneficiário de programas é cidadão. }\end{array}$ & $\begin{array}{l}\text { Avaliação sistêmica de programas sociais, orientada ao } \\
\text { aprendizado organizacional e inovação da gestão, com } \\
\text { emprego de várias metodologias, considerando a neces- } \\
\text { sidade de informação para diagnóstico, implementação } \\
\text { e avaliação somativa, realizada por equipes interna e ex- } \\
\text { terna, multidisciplinares, com pessoal com experiência na } \\
\text { gestão, com visão khuniana da ciência e reconhecimento } \\
\text { do caráter técnico-político da gestão pública. } \\
\text { Eficácia no cumprimento dos objetivos e efetividade so- } \\
\text { cial conferem legitimidade política para o programa. } \\
\text { Indicadores de programas aportam informações neces- } \\
\text { sárias aos diferentes momentos do programa e de seus } \\
\text { componentes sistêmicos, informando, quanto a resulta- } \\
\text { dos, aspectos sobre cobertura, equidade, qualidade dos } \\
\text { serviços e coesão social. }\end{array}$ \\
\hline
\end{tabular}

Fonte: Elaboração do autor a partir de Arretche (1995), Moreno et al. (2014) e Jannuzzi (2016).

\section{A PRODUÇÃO DE INDICADORES DE AVALIAÇÃO SISTÊMICA DE POLÍTICAS E PROGRAMAS SOCIAIS COMPLEXOS}

Muito além de indicadores de impacto, certamente importantes para avaliação da efetividade dos programas, gestores e técnicos precisam de indicadores sociais para diagnósticos adequados, indicadores de monitoramento de processos e de avaliação dos produtos e "entregas" realizadas, além de indicadores de capacidade de gestão e implementação de políticas e programas. Parece óbvio, mas é bom reiterar: entender melhor os bons e maus resultados dos programas sociais requer não apenas instrumentos que escrutinizem mais detalhadamente esses resultados - como acontece no 
4 É nessa perspectiva que o Instituto Nacional de Estudos e Pesquisas Educacionais vem investindo, depois de muito tempo prisioneiro das medidas de desempenho escolar. Ver Brasil (2014a) campo educacional com os exames de desempenho escolar como Saeb, Prova Brasil e Pisa, por exemplo -, mas também informação sobre todos componentes sistêmicos do programa - no caso, indicadores de caracterização das condições socioeconômicas dos alunos, das condições de infraestrutura das escolas, sobre a qualificação e condições de trabalho do corpo docente, as taxas de evasão, aprovação, etc. ${ }^{4}$

$\mathrm{O}$ retrato da realidade social apresentado pelo mosaico de indicadores será ainda mais útil se for seletivo - e não exaustivo -, reunindo as medidas referidas às dimensões mais estratégicas, organizadas em temas de um diagnóstico socioeconômico. Um bom diagnóstico para programas públicos deve contemplar o levantamento de informações sobre as características do público-alvo a ser atendido, as condições sociais do contexto em que vive, as potencialidades e fragilidades da base econômica local e regional (que podem criar condições melhores ou mais desafiadoras para o programa), os condicionantes ambientais (que restringem certas estratégias de desenvolvimento e potencializam outras) e o nível de participação da sociedade (que podem garantir maior controle social dos recursos e dos resultados dos programas). A amplitude temática de um bom diagnóstico é sempre uma decisão crítica: muito abrangente, perde-se o foco, a objetividade; muito restrito, pode comprometer a formulação do programa público, ao não explicitar as dimensões que determinam ou afetam a problemática social em questão.

De modo geral, na elaboração de diagnósticos socioeconômicos para programas públicos empregam-se indicadores sociais de várias áreas temáticas analíticas ou de atuação governamental. Afinal, para desenvolver programas no campo da educação básica, por exemplo, é preciso conhecer não apenas as condições de acesso à escola, a infraestrutura escolar e o desempenho dos alunos, mas também aspectos relacionados às condições de vida dos estudantes, tais como as condições de moradia, nível de pobreza e rendimento familiar, acesso a serviços de saúde e escolaridade dos pais, fatores esses que certamente podem afetar ou potencializar as ações programáticas específicas. Também devem fazer parte do diagnóstico os indicadores demográficos, em especial aqueles 
que permitam apresentar as tendências de crescimento populacional passado e as projeções demográficas futuras, já que possibilitam o dimensionamento dos públicos-alvo dos diversos programas no futuro. Demandas sociais dependem do perfil demográfico da população: os jovens requerem esforços de alocação e recursos em educação; os mais idosos demandam serviços assistenciais e previdenciários.

Indicadores sociais para diagnóstico não são necessariamente boas medidas para monitoramento e avaliação de políticas no curto e médio prazos. Diagnósticos apoiam-se, em geral, em indicadores de estoque; monitoramento e avaliação regular de políticas demandam medidas que reflitam fluxos e processos. No longo prazo, indicadores de diagnóstico podem ser úteis para avaliar o esforço do conjunto de estratégias desenhadas para colocar em ação a política social em questão. Afinal, políticas e programas efetivos são desenhados para mitigar a questão social originária, valendo-se de estratégias com maiores chances de se viabilizarem no contexto de recursos, governabilidade política e competência técnica existente.

Como discutido mais amplamente em Jannuzzi (2016), indicadores de monitoramento e avaliação de políticas e programas - ou de forma mais simplificada, indicadores de políticas e programas - precisam ser específicos e sensíveis aos objetivos e aos vários componentes programáticos dos mesmos, para mostrar efeitos - ausência de efeitos ou mesmo os defeitos - quando existe razão para suspeitar que eles tenham sido produzidos. Para tornar mais clara essa assertiva, vale citar dois exemplos: se escolaridade média é um bom indicador social para retratar diagnósticos de condições de vida no Brasil, a frequência escolar de crianças de 4 e 5 anos, o abandono no ensino médio e a defasagem idade/série - medidas disponíveis e atualizadas regularmente no país (INSTITUTO BRASILEIRO DE GEOGRAFIA E ESTATÍSTICA - IBGE, 2014) são indicadores muito mais específicos e sensíveis para captar a efetividade de políticas educacionais. Da mesma forma, se esperança de vida é um bom indicador de diagnóstico ou avaliação a longo prazo da mudança de estilos de vida e do acesso a serviços de saúde de diferentes naturezas, indicadores 
de mortalidade infantil ou bem-estar físico reportado podem ser medidas melhores para monitoramento e avaliação regular de existência e oferta de programas de saúde pública.

Indicadores de diagnóstico prezam pela capacidade de explicação de alguma questão social ou de discriminação de situações típicas em que tal questão se manifesta em grupos populacionais ou territórios, em um momento específico do tempo. Indicadores de políticas devem refletir com mais sensibilidade e especificidade os efeitos - ou falta de efeitos - de ações e programas por elas desencadeados, medidos ao longo do tempo. Sincronia é atributo básico dos indicadores de diagnóstico; a diacronia é fundamental nos indicadores de monitoramento e avaliação de políticas. Indicadores sociais se legitimam pela capacidade de diferenciação territorial em dado momento e os indicadores de políticas, pela capacidade de diferenciação antes/depois das ações implementadas, em pelo menos dois momentos, portanto.

Indicadores de monitoramento e avaliação deveriam, assim, refletir os objetivos e desenho de políticas e programas específicos. Tome-se, como exemplo, o caso das políticas de desenvolvimento social e superação da pobreza. Se a natureza da intervenção envolve a formulação de programas de suplementação alimentar, com distribuição de leite a crianças ou de cestas básicas às famílias, são requeridas idealmente medidas diretas de nível de desnutrição, como indicadores antropométricos. Se o combate à fome contempla a implementação de programas de transferência de renda, ações de inclusão produtiva e políticas ativas de emprego (dinamização da economia, aumento real do salário mínimo, etc.), indicadores de pobreza monetária são úteis para monitoramento das taxas de cobertura da população potencialmente retirada do risco de exposição a esse flagelo. Se a estratégia inclui o provimento de alimentos por meio de merenda servida nas escolas ou de equipamentos de segurança alimentar - restaurantes populares, banco de alimentos, etc. -, indicadores de acesso a itens alimentares específicos podem trazer subsídios relevantes para avaliação. Se, na estratégia de combate à pobreza, são acopladas intervenções de natureza político-institucional para mitigar efeitos da estigmatização 
ou discriminação a que estão sujeitas as populações mais pobres, indicadores de percepção subjetiva de sua condição social podem ser importantes. Enfim, se o desenho do programa voltado à mitigação da pobreza é mais abrangente, contemplando diferentes ações setoriais de políticas sociais, as medidas de pobreza multidimensional ou um conjunto mais amplo de medidas de pobreza podem ser mais úteis para acompanhamento da estratégia.

A escolha de medidas mais específicas e sensíveis às intervenções dos programas sociais não deve ser entendida como uma armadilha ou falácia tautológica. É da natureza de indicadores de monitoramento e avaliação assim serem especificados; do contrário, não permitiriam analisar a eficácia do programa, tal como desenhado, para mitigar a questão social que o inspirou. Naturalmente, à medida que se avança no conhecimento da problemática social em questão, da eficácia ou não de determinadas ações, a partir dos indicadores de que se dispõe, pode-se revisar concepções anteriores e redefinir os problemas a serem enfrentados, construindo novos indicadores mais válidos para retratar a questão "ressignificada” e, daí, novos tipos de intervenções programáticas. Indicadores, assim como políticas e programas, também têm seu ciclo de vida, da inovação à obsolescência.

Além de indicadores sociais na elaboração de diagnósticos e de indicadores de programas para acompanhamento de suas atividades, produtos e efeitos, o sucesso de uma política ou programa depende da disponibilidade de informações acerca da capacidade de gestão e implementação dos agentes públicos envolvidos, nos diferentes contextos de atuação. Indicadores de estrutura de gestão e de oferta de serviços referem-se, principalmente, à caracterização dos recursos humanos - dimensionamento, formação, valores, etc. -, dos equipamentos sociais usados - adequação física, acessibilidade, cobertura territorial, etc. - e dos recursos orçamentários - suficiência, regularidade de desembolso, etc. Propostas meritórias de programas, com desenhos lógicos consistentes "em tese", podem ser inviabilizadas pelos problemas de implementação decorrentes de baixa capacidade de gestão de agentes encarregados da operação em um dos "nós críticos" 
do programa, em municípios, estados ou departamento encarregado em um Ministério. Indicadores de estrutura de gestão e de oferta de serviços permitem antecipar situações de baixa capacidade de oferta e ajustar o desenho do arranjo operacional do programa para o quadro existente.

Diagnósticos sobre características dos públicos-alvo e seus contextos sociais e econômicos de vivência, complementados com avaliações ex-ante da capacidade de gestão dos agentes públicos envolvidos, permitem avaliar criticamente a viabilidade operacional da proposta de programa para determinada problemática social e antecipar a necessidade de ajustes do seu desenho para diferentes contextos de demanda (segundo o público-alvo) e de oferta (segundo agente local). Com base em indicadores ou tipologias dessas duas dimensões - características socioeconômicas e capacidade de gestão -, podem ser construídas estratégias de implementação dos programas adequados aos diferentes desenhos operacionais de um programa social - mais simples ou mais complexo - em unidades territoriais (estados, municípios ou instituições) de maior ou menor estrutura e experiência administrativa. Afinal, se o programa tem desenho complexo, que requer a existência de equipe multifuncional, com qualificação específica e equipamentos adaptados, não seria mais adequado definir um plano de implantação do mesmo começando por aqueles estados, municípios e/ou instituições com os requisitos necessários? Ao mesmo tempo, não seria o caso de iniciar um projeto complementar que supra a necessidade de estruturação daquelas unidades que carecem das condições de implantar o programa? Não seria interessante desenvolver módulos específicos do programa para as unidades territoriais menos prioritárias para o programa?

Enfim, avaliações sistêmicas induzem a busca de informações e indicadores que possam responder às necessidades de conhecimento ao longo do ciclo de implementação dos programas, cobrindo seus vários componentes sistêmicos e objetivos almejados, como sistematizado no Quadro 2. Produzir esse conjunto de indicadores envolve a extração de dados de um conjunto amplo de pesquisas primárias, registros administrativos e cadastros públicos, constituindo um plano de avaliação, em geral, de alguns anos (BRASIL, 2016). 
QUADRO 2: Matriz de indicadores de avaliação sistêmica de políticas e programas sociais

\begin{tabular}{|c|c|c|c|}
\hline $\begin{array}{l}\text { COMPONENTE SISTÊMICO } \\
\text { E OBJETIVOS ALMEJADOS } \\
\text { DA POLÍTICA E } \\
\text { PROGRAMA SOCIAL }\end{array}$ & $\begin{array}{l}\text { FORMULAÇÃO DA } \\
\text { POLÍTICA E PROGRAMA: } \\
\text { INDICADORES SOCIAIS, } \\
\text { INDICADORES DE } \\
\text { DIAGNÓSTICO DE } \\
\text { PÚBLICOS-ALVO E DE } \\
\text { CAPACIDADE DE GESTÃO }\end{array}$ & $\begin{array}{l}\text { IMPLEMENTAÇÃO DA } \\
\text { POLIITICA OU PROGRAMA: } \\
\text { INDICADORES DE INSUMO, } \\
\text { PROCESSO E PRODUTOS/ } \\
\text { SERVIÇOS OFERTADOS }\end{array}$ & $\begin{array}{l}\text { AVALIAÇÃO SOMATIVA DA } \\
\text { POLIITICA OU PROGRAMA: } \\
\text { INDICADORES DE } \\
\text { RESULTADOS E IMPACTOS } \\
\text { SOBRE O PÚBLICO-ALVO E } \\
\text { SOCIEDADE }\end{array}$ \\
\hline \multicolumn{4}{|l|}{$\begin{array}{l}\text { Cobertura, equidade, } \\
\text { coesão social }\end{array}$} \\
\hline \multicolumn{4}{|l|}{ Recursos orçamentários } \\
\hline \multicolumn{4}{|l|}{$\begin{array}{l}\text { Recursos humanos } \\
\text { envolvidos }\end{array}$} \\
\hline \multicolumn{4}{|l|}{$\begin{array}{l}\text { Equipamentos físicos e } \\
\text { materiais }\end{array}$} \\
\hline \multicolumn{4}{|l|}{$\begin{array}{l}\text { Serviços e produtos } \\
\text { ofertados }\end{array}$} \\
\hline \multicolumn{4}{|l|}{$\begin{array}{l}\text { Governança e arranjos } \\
\text { institucionais }\end{array}$} \\
\hline Participação social & & & \\
\hline
\end{tabular}

Fonte: Jannuzzi (2016).

\section{AVALIAÇÃO SISTÊMICA DO PRONATEC: AS PESQUISAS REALIZADAS E INDICADORES ILUSTRATIVOS}

A avaliação de programas públicos de qualificação profissional envolve um esforço metodológico considerável, requerendo diferentes pesquisas e estudos sobre seus públicos-alvo, processos operacionais e resultados. Esse é o caso do Programa Nacional de Acesso ao Ensino Técnico e Emprego, em especial sua modalidade Bolsa Formação - Plano Brasil Sem Miséria, que contou com um desenho inovador em termos de estratégia de mobilização de públicos, definição de pauta municipal de cursos e de cobertura territorial pelo país, requerendo uma estratégia sistêmica de avaliação, aqui brevemente ilustrada.

O Pronatec foi instituído por meio da Lei n. 12.513, de 26 de outubro de 2011, com o objetivo de expandir, interiorizar e democratizar a oferta de cursos de educação profissional e tecnológica, visando à melhoria da qualidade do ensino médio, ampliar as oportunidades educacionais aos trabalhadores e, assim, promover a inclusão social, a inovação tecnológica e o aumento da produtividade e competitividade da economia. Como registram Galindo, Feres e Schroeder (2015), o programa articulou diversas ações relacionadas à 
5 Vale registrar que o Plano BSM envolveu, de 2011 a 2015, a realização de mais de uma centena de ações, em três eixos programáticos: ações de garantia de renda, acesso a serviços sociais e iniciativas de inclusão produtiva, na qual o Pronatec BSM se encaixava. Ver Campello, Falcão e Costa (2014) educação profissional e tecnológica, no âmbito do governo federal, como a Expansão da Rede Federal de Educação Profissional, Científica e Tecnológica; o Acordo de Gratuidade com o Sistema S e a promoção da Bolsa-Formação, para dar escala à oferta gratuita de cursos técnicos e de formação inicial e continuada (FIC), com recursos repassados pelo MEC. Desde o seu lançamento até o final de 2014, foram realizadas mais de 8 milhões de matrículas, sendo 2,3 milhões em cursos técnicos e 5,8 milhões em cursos FIC. Desses últimos, cerca de 1,3 milhão foram destinados prioritariamente aos públicos do Plano Brasil Sem Miséria (BSM), configurando o que denominou o Pronatec BSM. ${ }^{5}$

O desenho operacional do Pronatec BSM previa uma série de etapas, envolvendo vários agentes no setor público e Sistema S (MULLER et al., 2015). Naturalmente, tudo começava mediante a alocação anual de recursos orçamentários do Plano Brasil Sem Miséria no MEC, para oferta de cursos de qualificação profissional para os públicos-alvo das ações do MDS, em especial jovens, mulheres e adultos inscritos no Cadastro Único de Programas Sociais, beneficiários ou não do Bolsa Família. As prefeituras deveriam aderir formalmente ao programa, para que pudessem registrar demandas de cursos, ajustados às características e dinâmica do mercado de trabalho local, e também divulgar e mobilizar, via Centros de Referência da Assistência Social, os alunos em potencial, depois de homologadas as vagas nos cursos pleiteados. Em vários municípios, estruturaram-se equipes específicas de mobilização, as equipes do Programa Nacional de Acesso ao Mundo do Trabalho (Acessuas-Trabalho), com estratégias intensivas de comunicação social em rádio, televisão, contato telefônico e visita domiciliar de famílias inscritas no Cadastro. Seguiam-se, então, a pré-matrícula dos interessados nos postos de atendimento ou nas próprias unidades ofertantes e o chamamento para matrícula nos cursos que apresentavam o nível mínimo de demanda. Tendo-se iniciado o curso, a unidade ofertante registrava a frequência às aulas, o desempenho escolar dos alunos e, desejavelmente, comunicavam às equipes de assistentes sociais as situações de evasão e dificuldades que os alunos estavam enfrentando no atendi- 
mento aos cursos. Essas equipes tinham também a responsabilidade de buscar a articulação local com outras políticas de emprego e renda, como a intermediação de mão de obra, acesso ao microcrédito, formalização de microempreendedores e assistência técnica. Dessa forma, esperava-se que o egresso do curso já pudesse estar mais próximo de aproveitar sua formação em novo negócio, novo emprego, ou mesmo na formalização do vínculo empregatício existente.

Um plano de avaliação abrangente para uma intervenção pública com essa complexidade envolve diagnósticos de públicos-alvo potenciais, análises institucionais sobre a coordenação federativa e sobre a articulação setorial para implementação do programa nos municípios, além de avaliações de egressos participantes por meio de metodologia quasi-experimental (Diagrama 1). Também envolve a avaliação da efetividade das atividades de mobilização dos alunos, da extensão de cobertura territorial da oferta, do acesso efetivo dos públicos do BSM, da adequação da oferta diante das demandas de mercado de trabalho regional, da qualidade do material didático, do desempenho dos participantes e da satisfação na realização dos cursos. Trata-se, pois, de um bom exemplo de avaliação sistêmica. 


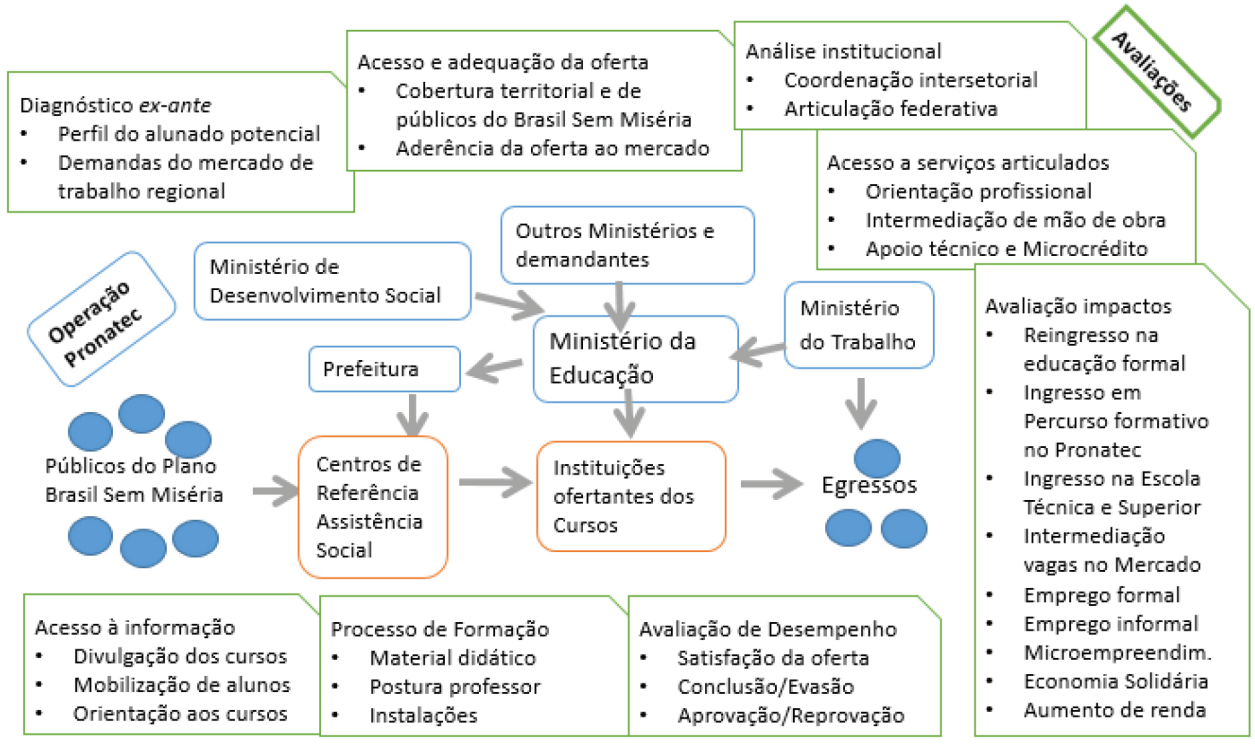

Por iniciativa ou delegação do MDS, vários estudos nessas temáticas foram realizados pela Secretaria de Avaliação e Gestão da Informação (Sagi) entre 2011 e 2016, por meio de um conjunto amplo de estratégias metodológicas, produzindo um conjunto significativo de evidências acerca do programa. Para fins ilustrativos, alguns resultados dessas pesquisas foram sistematizados no Quadro 3, não por serem os mais importantes, mas pelo fato de permitirem representar algumas das dimensões avaliativas que se devem valorizar em programas sociais, como cobertura territorial, equidade de acesso, efetividade. Os relatórios e publicações com resultados são também citados, nos quais se poderá ter um quadro mais geral da metodologia da pesquisa e dos seus resultados. Montagner e Muller (2015) apresentam uma sistematização dos principais achados das pesquisas.

Uma das primeiras pesquisas realizadas foi motivada pela necessidade de conhecer a experiência, práticas e iniciativas das secretarias municipais de Assistência Social no campo da inclusão produtiva e na oferta de cursos de qualificação profissional. Com o lançamento do Plano Brasil Sem 
Miséria, em junho de 2011, várias iniciativas estavam sendo desenhadas na área e era necessário dispor de informações e indicadores que permitissem avaliar a capacidade de gestão instalada na oferta e gestão de programas de qualificação profissional e inclusão produtiva. Nas décadas anteriores, a oferta de qualificação profissional estivera restrita aos cerca de 200 municípios mais populosos, com maior concentração da força de trabalho e produção econômica. Para que os cursos de qualificação profissional alcançassem os médios e pequenos municípios no interior do país e, assim, chegassem aos públicos mais vulneráveis do Bolsa Família e outros programas do MDS, era preciso identificar onde havia equipe técnica local que pudesse ser envolvida.

Essa demanda levou à estruturação de questionário específico sobre inclusão produtiva, para aplicação no Censo anual do Sistema Único da Assistência Social (Censo Suas) em 2011. O engajamento dos gestores municipais do Suas em responder esse levantamento, iniciado em 2007, por formulário na Internet, garantiu a disponibilização de informações para a quase totalidade dos municípios brasileiros (5.416 dos 5.565 municípios na época, $97 \%$ de resposta). No estudo preliminar com resultados do levantamento, Martignoni (2011) apontou que cerca de 4,4 mil municípios (81\% dos respondentes) haviam declarado desenvolver programas de capacitação e qualificação profissional. Foi um resultado recebido com certa surpresa, já que o Pronatec BSM havia se concentrado em apenas 192 munícipios (3\%) em 2011. A análise do perfil da oferta de cursos indicava, contudo, que cerca de um terço das vagas concentrava-se em artesanato, bricolagem e outras temáticas relacionadas. Não parecia haver, pois, correspondência entre oferta de qualificação e dinâmica de mercado de trabalho, já que não eram as ocupações associadas a essas atividades que as estatísticas de emprego formal do Ministério do Trabalho apontavam como mais dinâmicas. Enfim, parecia haver possibilidades de expansão do Pronatec BSM para um número muito maior de municípios, desde que asseguradas as condições de oferta por instituições com experiência (como os institutos federais e o Sistema S) e também maior aderência à dinâmica regional do mercado 
de trabalho. Para tanto, a Sagi passou a produzir, desde então, boletins regulares sobre as ocupações mais dinâmicas em todos os municípios brasileiros, disponibilizando-os em seu portal na Internet.

Levantamentos similares foram realizados nos anos seguintes, incorporando detalhamentos acerca da presença de equipes do Acessuas-Trabalho e atividades de articulação com outras políticas de emprego e renda, como encaminhamento para intermediação de mão de obra, serviços de microcrédito, etc. Os resultados do Censo Suas 2014 mostraram que o Pronatec BSM já havia alcançado 4.024 municípios (72\%) e que equipes do Acessuas já atuavam em $26 \%$ dos municípios (BRASIL, 2015). Isso deve explicar o fato de que, em $25 \%$ dos municípios, havia a prática de encaminhamento de pessoas para o Sistema Nacional de Emprego (Sine). Este levantamento permitiu não apenas avaliar a cobertura do Pronatec BSM, como também constatar a complexificação da oferta de serviços associados. Tratou-se, pois, de uma avaliação de processo, com indicações importantes da necessidade de reforçar a capacitação técnica em municípios menores.

A avaliação da cobertura do Pronatec e da existência de outras 20 modalidades de inclusão produtiva urbana e rural foi também tema na Pesquisa de Informações Básicas Municipais do Instituto Brasileiro de Geografia e Estatística (IBGE) (Munic), em 2014. Era necessário dispor de uma avaliação da cobertura do programa como um todo - não só o Pronatec BSM - e tendo como respondente não apenas o gestor municipal da Assistência Social, mas também os demais gestores que pudessem atuar na área (como as pastas de Desenvolvimento Econômico, Trabalho, Educação, etc.). Era necessário, ainda, dispor de um diagnóstico de capacidade de gestão mais amplo na área de inclusão produtiva, investigando as parcerias institucionais realizadas pelos municípios e a existência de oferta para os diversos públicos vulneráveis, tais como beneficiários do Bolsa Família, desempregados, população em situação de rua, etc. Tratava-se de insumo importante para a estruturação das novas iniciativas na área na segunda fase do Plano Brasil Sem Miséria, iniciada em 2015. Condizente com os resultados do Censo Suas 2014, a Munic apontou que $78 \%$ dos municípios operavam o 
Pronatec. Na qualificação profissional, os principais parceiros, depois do governo federal, eram os estados e o Sistema S (39\% dos municípios). As universidades e institutos federais ainda têm atuação restrita na área (26\%). Um dos resultados curiosos da pesquisa é que os beneficiários do Bolsa Família foram os públicos mais visados na oferta da qualificação pelos municípios (79\% deles), mais do que os desempregados (65\%). A mobilização da rede socioassistencial explica certamente esse resultado.

Embora já estivesse sendo implementado quando da divulgação dos primeiros resultados da Pesquisa de Avaliação de Ações em Desenvolvimento Social (Pads) em 2012, o Pronatec BSM ganhou legitimidade adicional - para além de ter sido um dos temas valorizados na disputa eleitoral em 2010 - com o fato de que, entre os entrevistados de menor poder aquisitivo (classe ED2) na amostra nacional do levantamento, somente $12 \%$ haviam tido a oportunidade de realizar um curso de qualificação profissional em sua vida (contra $47 \%$ de indivíduos na classe AB) (BRASIL, 2014b). Dentre os que haviam feito curso de qualificação profissional nos últimos três anos, 51\% pagaram do próprio bolso a formação. Inadequação do horário de oferta do curso - coincidente com a jornada de trabalho -, falta de recursos para deslocamento e dificuldade de acesso foram apontados como principais obstáculos à adesão ou frequência ao curso de qualificação, especialmente entre as pessoas de menor rendimento. Parcela bastante reduzida dos entrevistados buscou o Sine para encontrar um emprego. Cerca de $81 \%$ dos entrevistados que estavam frequentando ou haviam realizado curso há até três anos declararam que o curso havia sido importante para sua vida profissional, seja por terem conseguido emprego na área de formação, seja pelos contatos e indicações de empregos que se abriram na ocasião. Indicadores como esses são importantes para evidenciar a relevância social da questão e defender a presença do programa na agenda de prioridades de políticas públicas, além de trazerem insumos cruciais para o desenho da intervenção. O Pronatec teria que inovar em termos de cobertura territorial, horários de oferta de cursos e na articulação com as políticas de intermediação de emprego - para dizer o mínimo - para não replicar a realidade (baixa cobertura e iniquidade) apontada pela Pads. 


\begin{tabular}{|c|c|c|c|c|c|}
\hline 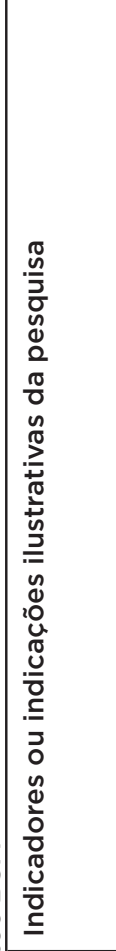 & 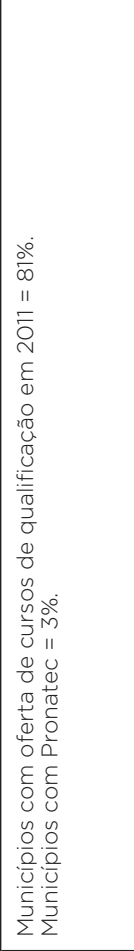 & 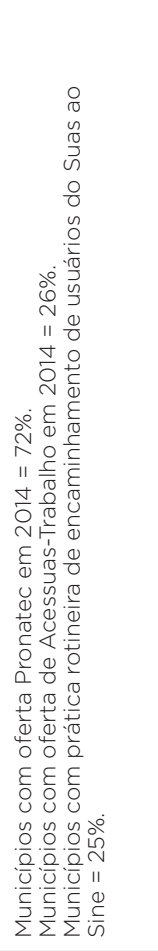 & 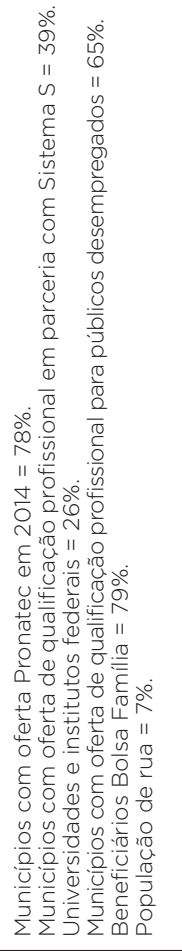 & 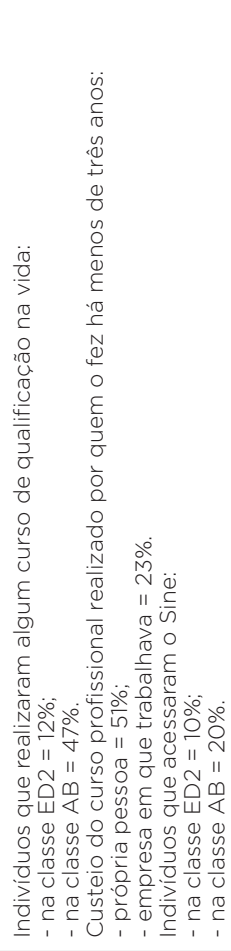 & 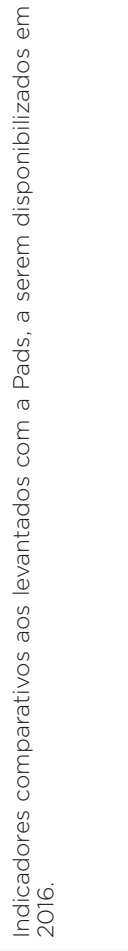 \\
\hline 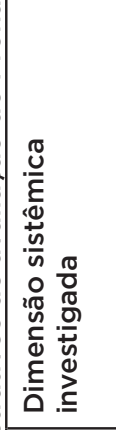 & 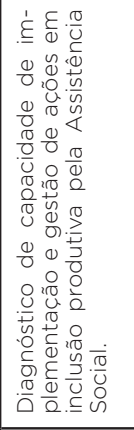 & 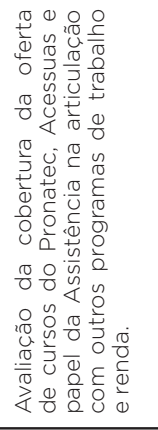 & 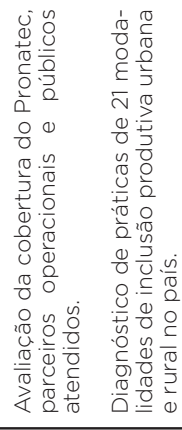 & 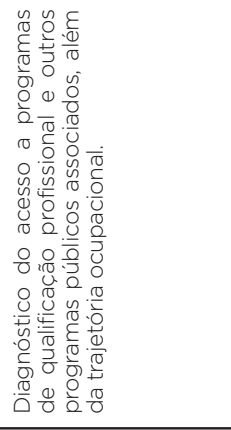 & 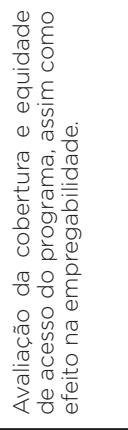 \\
\hline 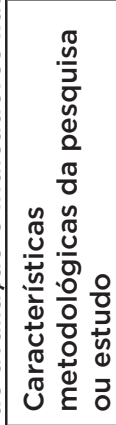 & 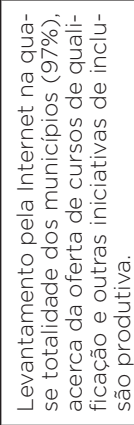 & 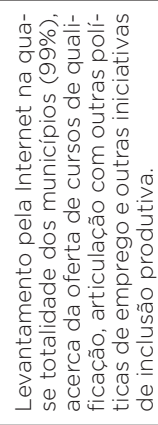 & 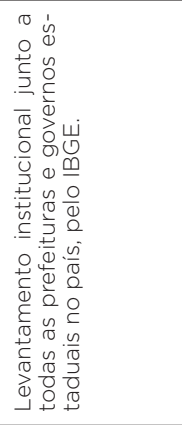 & 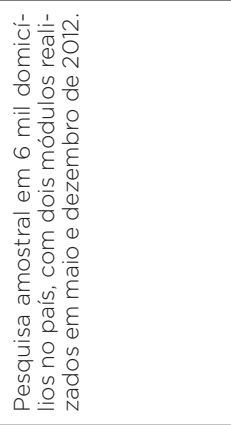 & 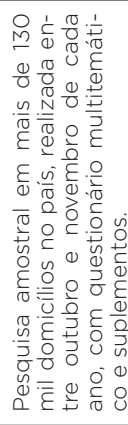 \\
\hline 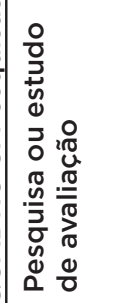 & 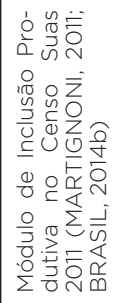 & 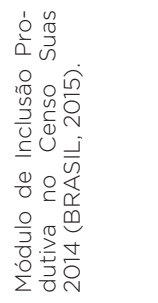 & 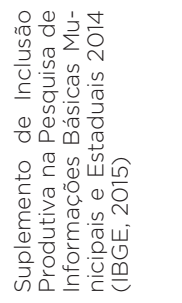 & 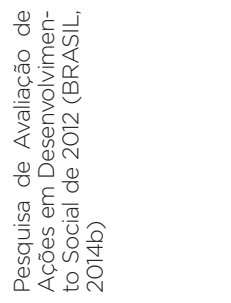 & 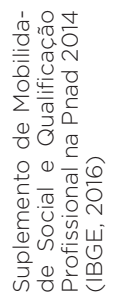 \\
\hline
\end{tabular}




\begin{tabular}{|c|c|c|c|c|}
\hline 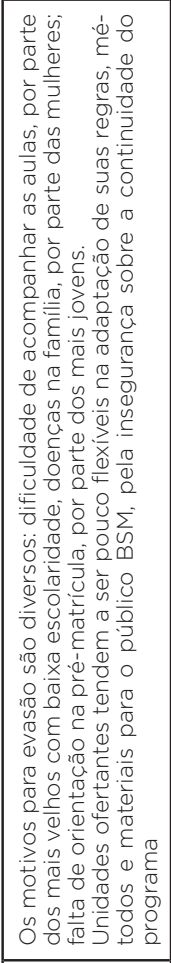 & 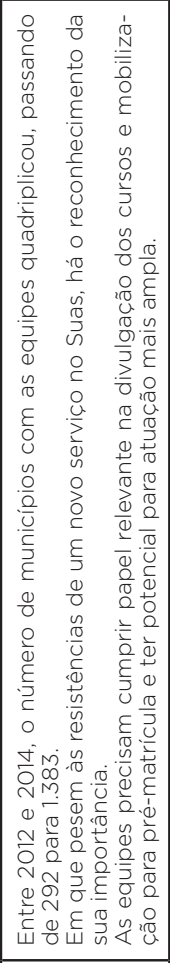 & 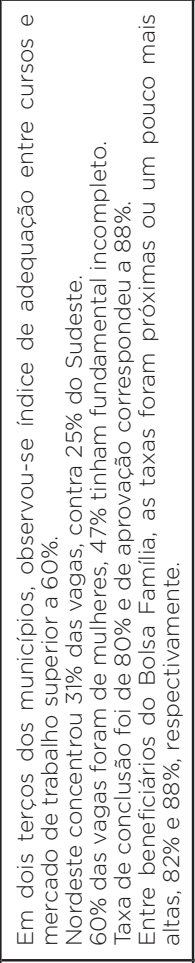 & 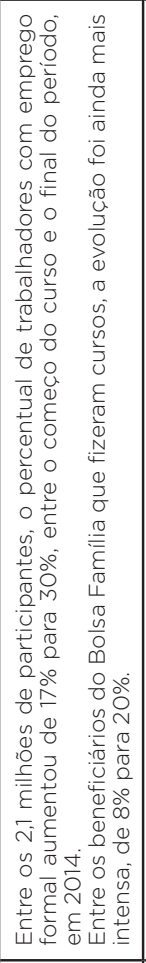 & 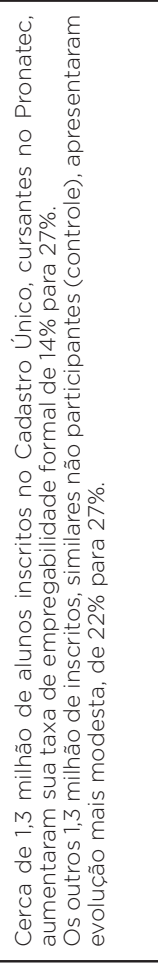 \\
\hline 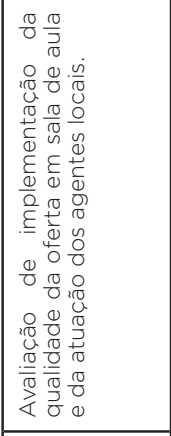 & 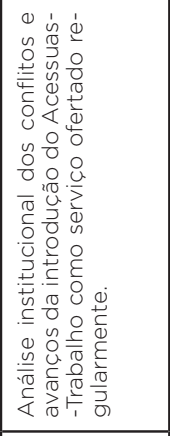 & 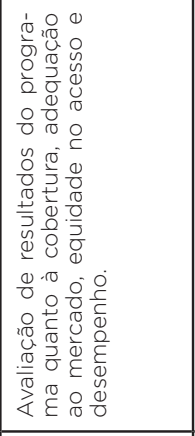 & 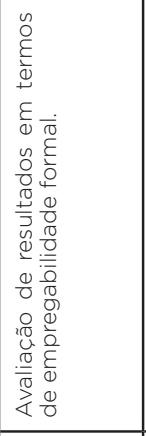 & 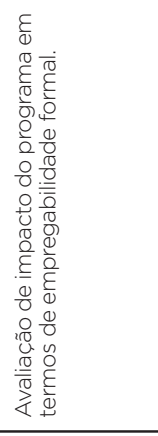 \\
\hline 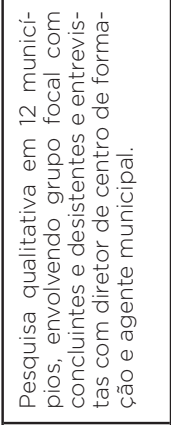 & 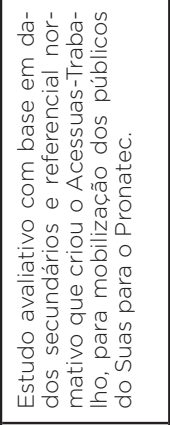 & 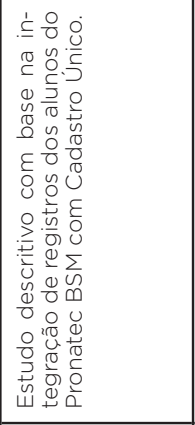 & 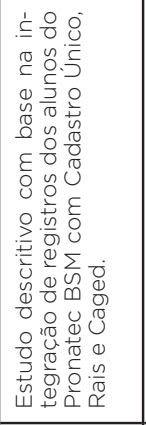 & 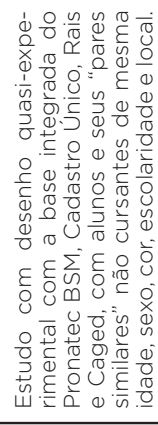 \\
\hline 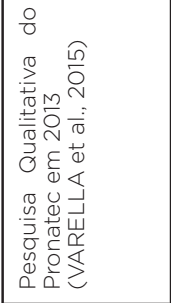 & 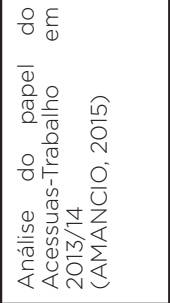 & 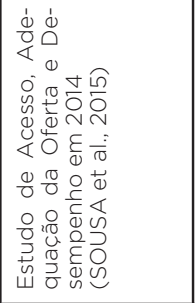 & 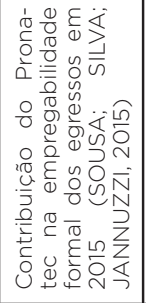 & 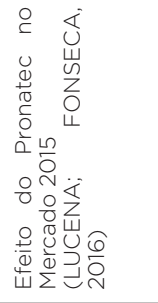 \\
\hline
\end{tabular}


A Pads também trouxe um conjunto amplo de informações acerca das estratégias de busca de emprego, sobre a trajetória ocupacional do entrevistado e mobilidade inter e intrageracional. São informações que poderão ser contrastadas com as provenientes do Suplemento de Mobilidade Social e Qualificação Profissional da Pesquisa Nacional por Amostra de Domicílios de 2014, quando vierem a público no final de 2016. Com isso, será possível construir indicadores de equidade de acesso, por região, rendimento, gênero e raça/cor, assim como avaliar a adequação do curso realizado e ocupação exercida. Os microdados disponibilizados poderão trazer evidência acerca do eventual efeito conjugado do programa com outros - Bolsa Família, por exemplo -, em termos de mobilidade ocupacional.

A estratégia de avaliação do Pronatec BSM contemplou também levantamentos sobre a implementação na ponta em 2013, para análise da adequação entre os cursos e o perfil dos alunos, motivos de desistência e o processo de especificação do elenco de cursos pela administração municipal (VARELLA et al., 2015). Para isso, empregaram-se metodologias qualitativas, como grupos focais com concluintes e desistentes, além de entrevistas com diretores das unidades de formação e gestores locais, responsáveis pelo programa. Entre os inúmeros achados da pesquisa, identificou-se que os grupos mais propensos à evasão eram os adultos mais velhos, que haviam procurado o Pronatec para certificação da ocupação que já exerciam e acabavam desestimulados pelas dificuldades de locomoção, de acompanhamento dos cursos em função da escolaridade mais baixa e pela resistência das unidades ofertantes em fazer as adaptações necessárias (por insegurança acerca da continuidade do programa). Entre as mulheres, a evasão era motivada pela necessidade de prestar apoio no domicílio. Entre jovens, as desistências estavam relacionadas às escolhas voluntaristas de cursos de qualificação, sem uma orientação mais adequada quando da pré-matrícula. Constatou-se nas entrevistas que gestores municipais do programa foram ganhando mais influência na definição da pauta de cursos, resistindo às ofertas preparadas pelas unidades ofertantes. 
O papel do Acessuas-Trabalho como recurso de divulgação dos cursos, mobilização de públicos dos programas e serviços do MDS e apoio aos alunos foi também investigado (AMANCIO, 2015). Em que pesem as resistências de absorção de mais um serviço na ponta, ele se revelou um componente importante do Pronatec, sem o que parcela da população mais vulnerável não teria conseguido obter informações e realizar o curso. O número de municípios com equipes do Acessuas-Trabalho expandiu-se muito rapidamente, passando de 292 para mais de 1.383, entre 2012 e 2014, o que revela o interesse das prefeituras em buscar beneficiários do Bolsa Família e usuários dos serviços do Suas para as oportunidades de formação no Pronatec.

Três estudos avaliativos realizados a partir da integração de dados dos alunos do Pronatec, dos inscritos no Cadastro Único e bases de emprego formal do Ministério do Trabalho (Rais e Caged) complementaram o conjunto de pesquisas na avaliação sistêmica do programa. Era necessário produzir indicadores acerca do perfil do alunado atendido, da aderência ou não da oferta em relação à dinâmica das ocupações pelo país afora, da equidade da oferta nas regiões e municípios mais pobres, de desempenho escolar dos participantes e, por fim, do eventual impacto na empregabilidade dos egressos. Em Sousa et al. (2015), produziram-se evidências da cobertura nacional do programa, com viés de equidade junto aos municípios menores e no Nordeste. Das 2,8 milhões de vagas analisadas no estudo, entre 2011 e 2014 , cerca de $860 \mathrm{mil}$ foram oferecidas nos municípios com até 50 mil habitantes. O Nordeste concentrou 31\% das vagas ofertadas (contra 25\% no Sudeste), seguindo a geografia dos inscritos no Cadastro Único e no Bolsa Família. O alunado do Pronatec BSM tinha maior parcela de mulheres (60\%) e elevado contingente de pessoas com fundamental incompleto (47\%). Em pouco mais de três anos, o programa se expandiu de pouco menos de 200 para 4 mil municípios, com nível crescente de similaridade da oferta de cursos com as tendências do mercado de trabalho local. De fato, dois terços dos municípios apresentaram um índice de similaridade igual ou superior a $60 \%$, cifra ainda mais elevada nas metrópoles. A taxa média de conclusão foi 
de $80 \%$, comparativamente mais elevada do que a de programas similares nos anos 1990. Contribuiu para isso a participação de beneficiários do Bolsa Família, mais propensos a se manter nos cursos até o final e com nível de aprovação de $88 \%$, igual à média geral.

Os dois outros estudos, de Sousa, Silva e Jannuzzi (2015), de natureza descritiva, e de Lucena e Fonseca (2016), de delineamento quasi-experimental (com grupo de alunos e outro de tratamento, criado à semelhança do primeiro), investigaram um dos possíveis impactos do Pronatec: o aumento da empregabilidade formal. Crescimento das chances de empregabilidade e elevação de rendimentos provenientes do trabalho são dois efeitos potencialmente esperados de participantes de programas de qualificação profissional. Embora esses programas tenham objetivos mais amplos como toda iniciativa pública no campo de formação educacional, o sucesso na obtenção de um emprego ou na efetivação em um posto antes temporário, ou, ainda, efeitos na promoção salarial são desdobramentos certamente desejáveis para aqueles que realizam e concluem tais programas. Contudo, esses efeitos não podem ser garantidos unicamente pela participação em programas de qualificação profissional. Eles dependem de outros condicionantes contextuais, como a dinâmica econômica e a oferta de novos postos de trabalho nas áreas de formação profissional realizadas, e também da existência de programas públicos associados à intermediação de mão de obra, ao apoio ao empreendedorismo e acesso a crédito, para citar alguns dos principais programas e ações a serem considerados. Os estudos avaliativos mencionados produziram evidências de que a participação no programa fez diferença para a inserção formal dos egressos, especialmente para beneficiários do Bolsa Família. A análise da trajetória de 1,3 milhão de egressos do programa, inscritos no Cadastro Único, relevou, que a parcela deles com emprego formal passou de $14 \%$ para $27 \%$, considerando o período de início do curso e a situação em meados de 2014. Uma amostra de mesmo tamanho, com indivíduos similares, selecionados por algoritmo probabilístico no Cadastro Único, com as mesmas características (idade, sexo, cor, escolaridade e município de 
residência), também registrou uma evolução positiva, mas menos virtuosa, já que a parcela com emprego formal teria passado de $22 \%$ para $27 \%$, no mesmo período. Teriam os 1,3 milhão de inscritos no Cadastro Único alcançado a mesma taxa de formalização sem a contribuição do Pronatec? Sem a participação no programa, teria sido possível para beneficiários do Bolsa Família aumentar a participação no mercado formal de $8 \%$ para 19\%, entre 2011 e 2014 ? Não há pesquisa de avaliação de impacto que consiga demonstrar o contrário, ou seja, que o programa não fez diferença para os públicos mais vulneráveis.

Enfim, esse conjunto de pesquisas e indicadores - acerca da cobertura, equidade de acesso, adequação da oferta, desempenho da oferta e impactos - coloca em relevo a perspectiva sistêmica da avaliação realizada para o Pronatec BSM, trazendo parâmetros para uma análise mais abrangente do mérito e relevância social do programa. Mais do que responder se o programa teve sucesso ou não, a avaliação sistêmica oferece uma narrativa do processo complexo com que ele se desdobrou no período. Se o Pronatec não tivesse uma estratégia de espraiar-se pelo território, não teria logrado alcançar os públicos mais vulneráveis da população brasileira, como mulheres e filhos jovens de famílias beneficiárias do Bolsa Família; como, até então, não haviam tido a oportunidade de realizar um curso de qualificação profissional, não surpreende o engajamento dos mesmos na conclusão e aprovação dos cursos, em nível um pouco acima da média; tal esforço, como o envolvimento de agentes locais e a disponibilidade de informações sobre dinâmicas regionais do mercado de trabalho, viabilizou uma oferta de cursos limitada, mas aderente às necessidades da economia local, favorecendo a inserção no mercado formal para volume significativo de egressos. Não houvesse o Pronatec com tais características, as chances de ingresso no mercado formal teriam sido muito menores para os públicos do Plano Brasil Sem Miséria.

Diferentes tipos de indicadores e informações foram produzidos para subsidiar as etapas de implementação, no diagnóstico de públicos e agentes operadores, no monitoramento de processos e avaliação de resultados e impactos. As 
pesquisas e estudos investigaram os componentes sistêmicos do programa, abordando análise das institucionalidades e agentes envolvidos, qualidade da oferta dos cursos quanto à didática do professor e qualidade do material e resultados efetivos quanto a taxas de evasão e conclusão. Para tanto, adotou-se uma abordagem multimétodos, com investigações qualitativas, pesquisas amostrais, produção de indicadores com base em registros administrativos e emprego de modelo quasi-experimental de avaliação de impacto na empregabilidade formal. Praticou-se a triangulação de sujeitos entrevistados ou analisados - alunos, egressos, docentes, técnicos municipais - cada qual com sua visão e apreciação do programa. Cada levantamento, cada técnica de pesquisa, cada sujeito, cada componente do programa analisado compuseram um mosaico de informações e indicadores que ajudaram a desnudar um aspecto da complexidade da intervenção, contribuindo para aprimorar suas ações e sua efetividade social, como se registrou em algumas passagens.

Uma investigação aos moldes dos "estudos antropológicos da produção científica nos laboratórios de pesquisa” (LATOUR, 2000) muito contribuiria para evidenciar como se processa a produção-apropriação-uso das informações e estudos nos círculos de gestão de programas sociais, permitindo vislumbrar como o campo da avaliação - entendida em sua perspectiva sistêmica - entremeia-se com a gestão que, por sua vez, redefine atividades e novas demandas de informação. O contexto do Pronatec seria muito propício nesse sentido, pelos personagens e agentes envolvidos, conteúdo técnico tratado e complexidade operacional.

\section{CONSIDERAÇÕES FINAIS}

Este texto procurou trazer elementos conceituais da abordagem sistêmica de avaliação de programas sociais, como estratégia de produção e disponibilização de informação e estudos abrangentes para aprimoramento de suas atividades, "entregas" e resultados, tomando como caso ilustrativo o Pronatec. Procurou-se, inicialmente, para fins didáticos, diferenciar avaliação sistêmica de avaliação com foco na 
legalidade dos procedimentos administrativos - como na auditoria operacional -, certamente necessária e obrigatória como atividade inerente à gestão de recursos públicos. Também se procurou diferenciá-la, sobretudo na apresentação do caso Pronatec BSM, de uma avaliação focada nas etapas finais do processo, de mensuração de impactos na empregabilidade formal de seus egressos - como na avaliação econômica de projetos sociais. Embora seja desejável dispor de indicadores nessa perspectiva, restringir a avaliação aos seus impactos é insuficiente diante dos objetivos do programa e do seu mérito como estratégia de inclusão social de públicos com problemas estruturais de inserção mais qualificada no mercado de trabalho. Indicadores de ineficiência, irregularidades no uso de recursos ou de impacto não são suficientes para julgar o mérito de um programa social complexo, mas sim para aprimorá-lo, a partir de avaliações e indicadores referidos a componentes específicos dos programas. Eventuais apontamentos de problemas formais de gestão, ineficiências em processos-meio ou constatações de baixo impacto são indicações importantes para correção de atividades, identificação de necessidades de capacitação de recursos humanos, de formalização de planos de trabalho e novas pesquisas.

Se é certamente desejável que políticas e programas públicos sejam escrutinizados por diferentes equipes e metodologias de avaliação, é preciso garantir que o debate sobre resultados de pesquisas seja feito de forma responsável, nos fóruns adequados, com abordagens adequadas à complexidade da intervenção e clareza acerca de valores, critérios e concepção de política social em questão. Parte das diferenças e disputas entre resultados de pesquisas de avaliação sobre um mesmo programa é, em primeira instância, de ordem metodológica. Tamanho e características da amostra analisada, dimensões investigadas e técnicas utilizadas levam, invariavelmente, a resultados diferentes em avaliações de programas. Mas outra fonte de discrepância entre avaliações está na finalidade política mais geral a que ela se presta, se para transparência e regularidade normativa da ação pública, se para mensuração da contribuição do programa à eficiência econômica dos recursos público ou se para aperfeiçoamento 
da política social, entendida como meritória em si mesmo. Concepções diversas da natureza da política social - e do papel do Estado - moldam escolhas de critérios avaliativos, de técnicas de investigação e, naturalmente, o tipo de indicadores a serem produzidos. Nesses casos não há como comparar resultados de pesquisa de avaliação, pois não compartilham pressupostos comuns ou um mesmo paradigma orientador, situação comum na produção do conhecimento científico, como bem demonstrou Kuhn (1992) há 50 anos.

Em oposição à ortodoxia clássica do recorte economicista da avaliação de projetos sociais, a abordagem sistêmica de avaliação aqui apresentada advoga pela importância de análises multidisciplinares e circunstanciadas para as problemáticas complexas que envolvem a produção dos serviços sociais na educação, saúde pública, qualificação profissional ou desenvolvimento social, para citar algumas das áreas mais proeminentes no campo de monitoramento e avaliação no país. Contrariamente à visão de que políticas sociais são mecanismos de correção de mercado, avaliações sistêmicas assentam-se nos valores constitutivos da cidadania social. Métodos de avaliação não se prestam a emular escolhas e preferências de consumidores racionais em mercados de produtos e serviços; destinam-se a produzir evidências para aperfeiçoamento do desenho, gestão e efetividade de programas públicos.

Enfim, antes de abandonar uma estratégia de política social, desenhada para atender a uma demanda social alçada à agenda de prioridades políticas pela eleição de novo dirigente do Executivo ou por pressão do movimento social ou de seus representantes no Parlamento, é preciso esforçar-se decididamente para que ela seja implementada da melhor forma possível. Produzir indicadores que retratem a complexidade sistêmica das políticas e programas é fundamental para isso. É nesse sentido que avaliações sistêmicas de programas sociais são necessárias, sobretudo em momentos em que o "tamanho do Estado" e amplitude das políticas sociais voltam ao primeiro plano do debate político nacional. O julgamento do mérito de políticas e programas sociais deve se pautar, para além de um critério-meio, como o da eficiência 
econômica, em critérios-fim que legitimam a ação estatal enquanto contribuição das políticas e programas para maior bem-estar, equidade e coesão social, valores republicanos inscritos em diversos artigos da Constituição Federal de 1988.

\section{REFERÊNCIAS}

AMANCIO, J. M. Inclusão produtiva e assistência social: desafios da implementação a partir das experiências recentes do Pronatec BSM e do Acessuas-Trabalho. Cadernos de Estudos Desenvolvimento Social em Debate, Brasília, DF, v. 24, p. 73-93, 2015.

ARRETCHE, M. Emergência e desenvolvimento do Welfare State: teorias explicativas. BIB: Boletim Informativo e Bibliográfico de Ciências Sociais, Rio de Janeiro, n. 39, p. 3-40, 1995.

ATKINSON, T. et al. Social indicators: the EU and social inclusion. Oxford: Oxford University, 2005.

BRASIL. Instituto Nacional de Estudos e Pesquisas Educacionais Anísio Teixeira. Indicador para mensurar a complexidade da gestão nas escolas a partir dos dados do censo escolar da educação básica. Brasília, DF: Inep, 2014a.

(Nota Técnica, n. 040/2014).

BRASIL. Ministério do Desenvolvimento Social e Combate à Fome. Pesquisa de avaliação de ações em desenvolvimento social: sumário executivo. Brasília, DF: MSD/Sagi, 2014b.

BRASIL. Ministério do Desenvolvimento Social e Combate à Fome. Censo do sistema único de assistência social. Brasília, DF: MSD/Sagi, 2015.

BRASIL. Ministério do Desenvolvimento Social e Combate à Fome. Sagi: informação e conhecimento para as políticas de desenvolvimento social. 1. ed. Brasília, DF: MSD/Sagi, 2016.

CAMPELLO, T.; FALCÃO, T.; COSTA, P. V. O Brasil sem miséria. Brasília, DF: MDS, 2014.

GALINDO, E. L.; FERES, M. M.; SCHROEDER, N. O Pronatec e o fortalecimento das políticas e educação profissional e tecnológica. Cadernos de Estudos Desenvolvimento Social em Debate, Brasília, DF, v. 24, p. 21-45, 2015.

HOWLETT, M.; RAMESH, M; PERL, A. Política pública, seus ciclos e subsistemas. Rio de Janeiro: Campus, 2013.

INSTITUTO BRASILEIRO DE GEOGRAFIA E ESTATÍSTICA. Síntese de indicadores sociais. Rio de Janeiro: IBGE, 2014.

INSTITUTO BRASILEIRO DE GEOGRAFIA E ESTATÍSTICA. Suplemento de inclusão produtiva da pesquisa de informações básicas municipais e estaduais. Rio de Janeiro: IBGE, 2015. 
INSTITUTO BRASILEIRO DE GEOGRAFIA E ESTATÍSTICA. Suplemento de qualificação profissional da pesquisa nacional por amostra de domicílios. Rio de Janeiro: IBGE, 2016.

JANNUZZI, P. M. Indicadores sociais no Brasil: conceitos, fonte de dados e aplicações. Campinas, SP: Alínea, 2004.

JANNUZZI, P. M. Avaliação de programas sociais: conceitos e referenciais de quem a realiza. Estudos em Avaliação Educacional, São Paulo, v. 25, n. 58, p. 22-42, 2014.

JANNUZZI, P. M. Monitoramento e avaliação de programas sociais: uma introdução aos conceitos e técnicas. Campinas: Alínea, 2016.

KUHN, T. A estrutura das revoluções científicas. São Paulo: Perspectiva, 1992.

LATOUR, B. Ciência em ação: como seguir cientistas e engenheiros sociedade afora. São Paulo: Unesp, 2000.

LUCENA, F. F. A.; FONSECA, J. C. G. Análise de impacto do Pronatec em beneficiários. Cadernos de Estudos Desenvolvimento Social em Debate, Brasília, DF, v. 25, p. 100-117, 2016.

MARTIGNONI, E. Inclusão produtiva no Censo Suas 2011: subsídios ao Pronatec BSM. Brasília, DF: Ministério do Desenvolvimento Social e Agrário, 2011. (Estudo Técnico Sagi, n. 05/2011).

MONTAGNER, P.; MULLER, L. H. Apresentação. Cadernos de Estudos Desenvolvimento Social em Debate, Brasília, DF, v. 24, p. 7-17, 2015.

MORAL-ARCE, I. Elección del método de evaluación cuantitativa de una política pública: buenas prácticas en América Latina y la Unión Europea. Madrid: EuroSocial, 2014. (Documentos de Trabajo, n. 6).

MORENO, L. et al. Los sistemas de bienestar europeos tras la crisis económica. Madrid: EuroSocial, 2014. (Estudios, n. 3).

MULLER, L. H. et al. Inclusão produtiva urbana no Plano Brasil Sem Miséria: a experiência do Pronatec. Cadernos de Estudos Desenvolvimento Social em Debate, Brasília, DF, v. 24, p. 46-72, 2015.

NEUFVILLE, J. I. Social indicators and public policy. New York: Elsevier, 1975.

RAVALLION, M. Should the randomistas rule? The Economists' Voice, v. 6, n. 2, p. 1-5, Feb. 2009.

SILVA, E. R. A. Projetos políticos e arranjos participativos nacionais: os significados e os desdobramentos no CNS e no Conanda. 2013. $251 \mathrm{f}$. Tese (Doutorado em Ciências Sociais) - Instituto de Filosofia e Ciências Humanas, Universidade Estadual de Campinas, Campinas, 2013.

SOUSA, M. F.; SILVA, Y.; JANNUZZI, P. M. Contribuição do Programa Nacional de Acesso ao Ensino Técnico e Emprego: bolsa formação para formalização do emprego e dos microempreendedores individuais: análise dos participantes beneficiários do Bolsa Família e inscritos no cadastro único. Cadernos de Estudos Desenvolvimento Social em Debate, Brasília, DF, v. 24, p. 162-185, 2015. 
SOUSA, M. F. et al. Avaliação do Pronatec: cobertura, adequação da oferta e desempenho dos participantes. Cadernos de Estudos Desenvolvimento Social em Debate, Brasília, DF, v. 24, p. 127-155, 2015.

VAITSMAN, J.; PAES-SOUSA, R. Avaliação de programas e transparência da gestão pública. Reflexões para Ibero-América: avaliação de programas sociais. Brasília, DF: Enap, 2009. p.11-23.

VARELLA, J. F. et al. Avaliação qualitativa do Pronatec-BSM; um estudo com egressos e desistentes, representantes das unidades ofertantes e interlocutores municipais. Cadernos de Estudos Desenvolvimento Social em Debate, Brasília, DF, v. 24, p. 94-126, 2015.

WEISS, C. Evaluation research. New Jersey: Prentice Hall, 1972.

YANES, P. La experiencia de evaluación de programas sociales en la Ciudad de México. Reflexões para Ibero-América: avaliação de programas sociais.

Brasília, DF: Enap, 2009. p. 79-88.

\section{PAULO DE MARTINO JANNUZZI}

Professor da Escola Nacional de Ciências Estatísticas do Instituto Brasileiro de Geografia e Estatística (Ence-IBGE), Rio de Janeiro, Rio de Janeiro, Brasil. Pesquisador em licença-capacitação no Instituto de Ciência Política da Universidade de Brasília (Ipol-UnB) e na Escola Nacional de Administração Pública (Enap), Brasília, Distrito Federal, Brasil paulo.jannuzzi.br@gmail.com 